\title{
Anatomical variant of the meniscus related to posterior junction: a case report
}

\author{
David Sadigursky ${ }^{1 *}$ (D), Lucas Cortizo Garcia', Rodrigo Rêgo Martins', Gustavo Castro De Queiroz², \\ Rogério Jamil Fernandes Carneiro ${ }^{1}$ and Paulo Oliveira Colavolpe ${ }^{1}$
}

\begin{abstract}
Background: There are several reports on anatomical differences of the meniscus. However, there are only a few reports on abnormalities in both menisci and anatomical differences in anterior cruciate ligament insertions.

Case presentation: This is a case report of a 36-year-old Hispanic man presenting symptoms, including knee pain, locking, and effusion, with an anatomical abnormality of the menisci corresponding to the fusion of the posterior horns of the menisci in tandem with the insertion of the posterior meniscus fibers in the anterior cruciate ligament.

Conclusions: This is the first study describing a meniscus anatomical variant with isolated posterior junction of the posterior horn with an anomalous insertion to the anterior cruciate ligament. The recognition of meniscus variants is important as they can be misinterpreted for more significant pathology on magnetic resonance images.
\end{abstract}

Keywords: Meniscus, Knee, Congenital, Anterior cruciate ligament

\section{Background}

Anatomical anomalies are commonly reported because of their importance in the development of conditions limiting daily physical activities. In addition, it is notable that the human meniscus presents with different kinds of anatomical abnormalities [1]; those frequently observed are a discoid meniscus (DM) and abnormalities of the meniscal horns [2]. Other malformations, including ring-shaped meniscus, meniscal ossicle, and insertional abnormality, are rare [3]. To the best of our knowledge, there are no reports on the fusion of meniscal posterior horns in tandem with the insertion of meniscal posterior fibers in the anterior cruciate ligament (ACL).

We report the first case of symptomatic anatomical meniscus alteration, presenting with a ring-shaped lateral meniscus concomitant with a fusion of posterior contours of menisci and insertion of meniscal posterior fibers in the ACL in a 36-year-old Hispanic man.

In the present case report, the patient's consent was obtained by the patient signing the Terms of Consent. The approval of the Research Ethics Committee of the

\footnotetext{
* Correspondence: davidsad@gmail.com

${ }^{1}$ Division of Knee Surgery, Clínica Ortopédica Traumatológica - COT, Salvador, Bahia, Brazil

Full list of author information is available at the end of the article
}

institution was also obtained. Data were collected between April 02 (2015) and August 28 (2015), the date of the patient's last visit. A review of articles on the subject was conducted using the following scientific platforms: PubMed, SciELO, Science Direct, Medline, and Google Scholar. The following keywords were used for the search: "knee pain" and/or "meniscal anatomic variants" and/or "meniscus anomaly" and/or "meniscus anatomy" and/or "meniscus abnormality."

\section{Case presentation}

A 36-year-old Hispanic man presented at our medical center with pain in his right knee of approximately 6 months' duration, along with knee locking and effusion. There was no history of trauma.

During a physical examination, he was in good health with no comorbidities or congenital diseases. During an orthopedic examination of his right knee, the range of motion was found to be preserved $\left(0\right.$ to $\left.155^{\circ}\right)$, with joint crepitation, and positive Steinmann and Merke tests results [4]. McMurray test result was negative; ligament tests were normal and there was no patellofemoral joint pain [5].

Magnetic resonance imaging (MRI), performed on 17 April 2015, revealed the following findings: a ring-shaped 

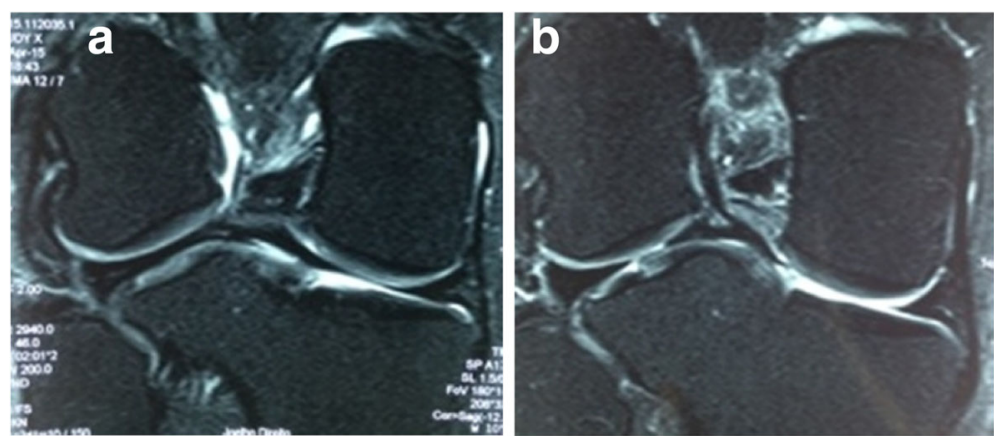

Fig. 1 a and $\mathbf{b}$ Magnetic resonance imaging in coronal T2 showing the meniscal variant of posterior junction and insertion to the anterior cruciate ligament

lateral meniscus, with small spots of radial rupture, adjacent to the free margin; degenerative changes in medial meniscus, emphasizing that there was a fusion of posterior contours of the menisci characterized as an anatomical variation; visible thinning of the ACL, including a part of its fibers from the posterolateral segment inserted in the posterior horn of the lateral meniscus (constitutional aspect; Figs. 1 and 2).

Our patient was initially treated using a conservative approach and a physiotherapy program. Because of persistent pain with mechanical blocking of maximum flexion, surgical treatment was indicated, with arthroscopy of his right knee, which was performed 4 months after the initial treatment began. During arthroscopic inspection, the following findings were highlighted: first, lateral meniscus with degenerative lesion in the posterior horn; and second, anatomical changes, that is, junction of both lateral and medial menisci posterior horn with interposition in the medial femoral condyle and insertion of meniscal fibers in the ACL (Fig. 3) were considered the cause of knee locking and of the presence of audible clicks.

A partial meniscectomy was performed, preserving the meniscal roots and decreasing the menisci interposition in the femorotibial joints, regulating the anatomical variation.
He developed no postoperative pain and the results were satisfactory.

\section{Discussion}

The present case describes a 36-year-old man who sought a consultation at an orthopedics hospital. He complained of knee pain associated with clamping and crepitation, common symptoms during every day clinical practice, except that, in this case, he had a finding of anatomical variation of the menisci on MRI showing fusion of posterior horns of the menisci and posterior insertion to the ACL.

Based on the normal anatomy of the menisci, they can be divided into three parts: body, anterior horn, and posterior horn. The function of both anterior and posterior horns is to secure the menisci in the tibia's plateau; these are critical structures for its biomechanical function $[6,7]$. Lesions in this region cause a loss in menisci biomechanical function, leading to an early degeneration of the articular cartilage, and, thereby, causing osteoarthritis $[8,9]$.

Among the morphological variations of the menisci, the most common is the DM, which probably has an embryological etiology. In DM, the meniscus shape resembles a disk instead of the usual shape (with an ascending shape), with greater incidence on the lateral meniscus $(77 \%)$ [10, 11]. Its clinical presentation is

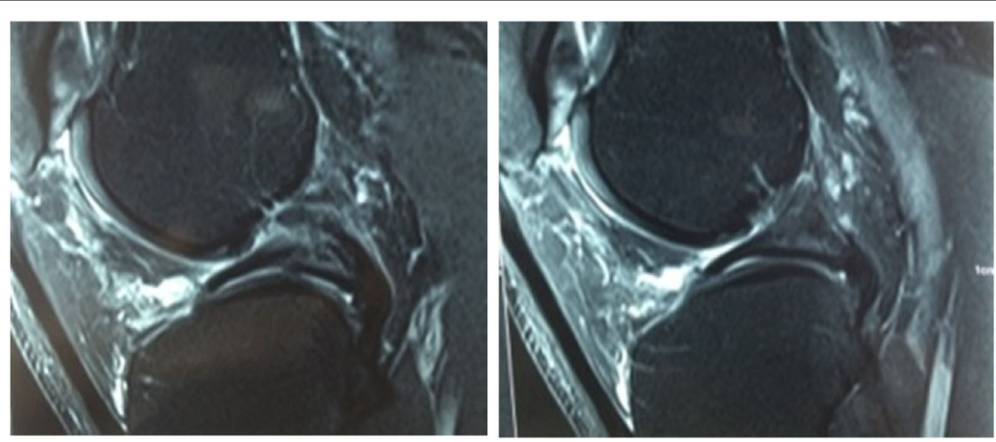

Fig. 2 Magnetic resonance imaging in sagittal T2 demonstrating the meniscal variant of posterior junction and insertion to the anterior cruciate ligament 


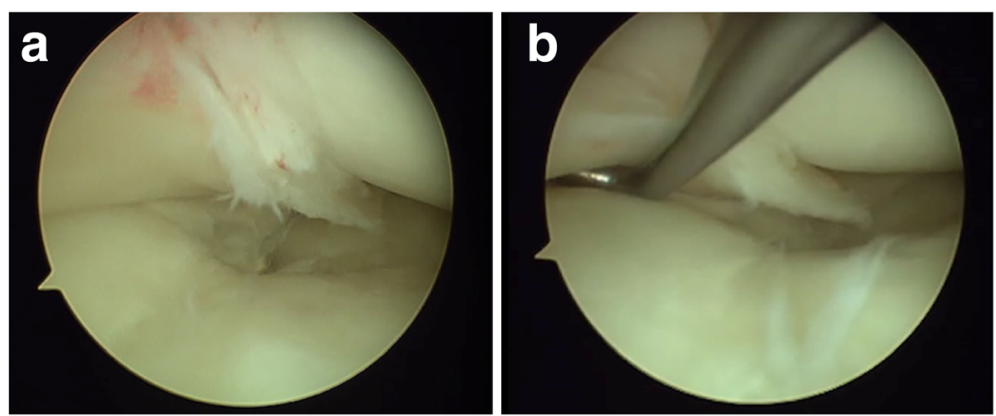

Fig. $\mathbf{3}$ a and $\mathbf{b}$ Arthroscopic images of the complete posterior junction of the posterior horns of the menisci

variable, from asymptomatic to the presence of pain, crepitation, and decreased range of motion, especially in children and young adults $[6,12]$. With the exception of the lateral meniscus, other malformations are infrequent, having a total incidence of $0.3 \%$ [13]. These anatomical changes may present as a meniscus with a ringed shape, having two layers, meniscal ossicle, or insertional abnormalities, such as anomalous insertion of the meniscus posterior horn into the ACL $[3,14]$.

The ring-shaped meniscus presents a circular form, with its external part being similar to the one of a normal meniscus: well-defined and angular, with no inner portion mobility, near the intercondylar notch. There is also a description of the meniscal ossicle, which is an uncommon alteration that normally occurs in the posterior horn of medial meniscus; it is defined as the presence of cortical and trabecular bone with bone marrow surrounded by meniscal fibrocartilage [15].

A study on the anatomy of the menisci anterior horns points to a change of its insertion in the ACL, identified in 35 knees from cadavers of Ghana's population [16]. The anomalous insertion of the medial meniscus anterior horn in the ACL may also occur in the posterior horn of the medial or lateral meniscus [17-19]. Other changes are much less frequent, with an incidence of $0.3 \%$ [13]. They are more frequent in the Asian population, and the lateral meniscus is the most affected. Mostly, these changes are asymptomatic $[1,20]$.

The meniscal variation presented in this study was not described in any other study on meniscal abnormalities. Additional investigation of similar cases is required so that a suitable description can be added among the possible anatomical variations of the menisci.

\section{Conclusions}

This is the first study describing a meniscus anatomical variant with isolated posterior junction of the posterior horn with an anomalous insertion to the ACL. The recognition of meniscus variants is important as they can be misinterpreted for more significant pathology on magnetic resonance images.

\section{Abbreviations \\ ACL: Anterior Cruciate Ligament; DM: Discoid meniscus; MRI: Magnetic resonance imaging}

\section{Acknowledgements}

Not applicable.

Funding

This research did not receive any specific grant from funding agencies in the public, commercial, or not-for-profit sectors.

\section{Availability of data and materials}

The datasets used and/or analyzed during the current study are available from the corresponding author on reasonable request.

\section{Authors' contributions}

DS, LCG, and RM were the main contributors in writing the manuscript and reviewing the literature. DS and PC performed the surgery. $G Q, R C$, and RM collected clinical data and reviewed the results. DS and PC performed a review of the manuscript and contributed to the study's intellectual concept. All authors read and approved the final manuscript.

\section{Ethics approval and consent to participate}

All procedures performed in studies involving human participants were in accordance with the ethical standards of the institutional and/or national research committee and with the 1964 Declaration of Helsinki and its later amendments or comparable ethical standards.

Our patient has signed terms of consent to participate in the research of this case report.

The institutional ethical committee has approved the publication of this case report.

\section{Consent for publication}

Written informed consent was obtained from the patient for publication of this case report and any accompanying images. A copy of the written consent is available for review by the Editor-in-Chief of this journal.

\section{Competing interests}

The authors declare that they have no competing interests.

\section{Publisher's Note}

Springer Nature remains neutral with regard to jurisdictional claims in published maps and institutional affiliations.

\section{Author details}

'Division of Knee Surgery, Clínica Ortopédica Traumatológica - COT, Salvador, Bahia, Brazil. ${ }^{2}$ Section of Medicine, Faculdade de Tecnologia e Ciências - FTC, Salvador, Bahia, Brazil. 
Received: 17 April 2017 Accepted: 9 November 2017

Published online: 18 December 2017

\section{References}

1. Aichroth PM, Patel DV, Marx CL. Congenital discoid lateral meniscus in children - a follow-up-study and evolution of management. J Bone Jt Surg-Br Vol. 1991;73(6):932-6.

2. Aagaard $H$, Verdonk R. Function of the normal meniscus and consequences of meniscal resection. Scand J Med Sci Sports. 1999;9(3):134-40.

3. Bhargava A, Ferrari D. Posterior medial meniscus-femoral insertion into the anterior cruciate ligament: a case report. Clin Orthop Relat. 1998;348:176-9.

4. Rossi R, Dettoni F, Bruzzone M, Cottino U, D'Elicio DG, Bonasia DE. Clinical examination of the knee: know your tools for diagnosis of knee injuries. Sports Med Arthrosc Rehabil Ther Technol SMARTT. 2011;3:25.

5. Azar FM, Canale ST, Beaty JH. Campbell's Operative Orthopaedics. 13th ed. Philadelphia: Elsevier. 2016;4.

6. Moraes DE. Meniscus morphometric study in humans. J Morphol Sci. 2010; 27(2):62-6.

7. Fox AJS, Wanivenhaus F, Burge AJ, Warren RF, Rodeo SA. The human meniscus: a review of anatomy, function, injury, and advances in treatment. Clin Anat. 2015;28:269-87.

8. Bonasia DE, Pellegrino P, D'Amelio A, Cottino U, Rossi R. Meniscal root tear repair: Why, when and how? Orthop Rev. 2015;7(2):5792.

9. Sakamoto F, Yamaguchi C. Raízes Meniscais : Anatomia e Avaliação por Meio da Ressonância Magnética. Rev Bras. 2007;47(5):370-5.

10. Davidson D, Letts M, Glasgow R. Discoid meniscus in children: Treatment and outcome. Can J Surg. 2003;46(5):350-8.

11. Jordan M. Lateral meniscal variants: evaluation and treatment. J Am Acad Orthop Surg. 1996;4(4):191-200

12. Kale A, Kopuz C, Edýzer M, Aydin ME, Demýr M, Ýnce Y. Anatomic variations of the shape of the menisci: a neonatal cadaver study. Knee Surg Sports Traumatol Arthrosc. 2006;14(10):975-81.

13. Fujikawa A, Amma H, Ukegawa Y, Tamura T, Naoi Y. MR imaging of meniscal malformations of the knee mimicking displaced bucket-handle tear. Skeletal Radiol. 2002;31(5):292-5.

14. Cha JG, Min KD, Han JK, Hong HS, Park SJ, Park JS, et al. Anomalous insertion of the medial meniscus into the anterior cruciate ligament: The MR appearance. Br J Radiol. 2008;81(961):20-4.

15. Simão M, Nogueira-Barbosa M. Magnetic resonance imaging in the assessment of meniscal anatomic variants and of the perimeniscal ligamentous anatomy: potential interpretation pitfalls. Radiol Bras. 2011; 44(Figure 2):117-22.

16. Brown AA. The insertion of the anterior horn of the medial meniscus: an anatomic study. Muscles Ligaments Tendons J. 2013;3(3):210-2.

17. Rainio P, Sarimo J, Rantanen J, Alanen J, Orava S. Observation of anomalous insertion of the medial meniscus on the anterior cruciate ligament. Arthrosc - J Arthrosc Relat Surg. 2002;18(2):E9.

18. Joshi D, Jain V, Goyal A, Bahl V, Chaudhary D. Discoid medial meniscus completely coalesced with the anterior cruciate ligament. Orthopedics. 2013:36(11):e1461-3.

19. Lee $\mathrm{BI}, \mathrm{Min} \mathrm{KD}$. Abnormal band of the lateral meniscus of the knee. Arthrosc - J Arthrosc Relat Surg. 2000;16(6):1-4

20. Rath $\mathrm{E}$, Richmond JC. The menisci: basic science and advances in treatment Br J Sports Med. 2000;34:252-7.

\section{Submit your next manuscript to BioMed Central and we will help you at every step:}

- We accept pre-submission inquiries

- Our selector tool helps you to find the most relevant journal

- We provide round the clock customer support

- Convenient online submission

- Thorough peer review

- Inclusion in PubMed and all major indexing services

- Maximum visibility for your research

Submit your manuscript at www.biomedcentral.com/submit 